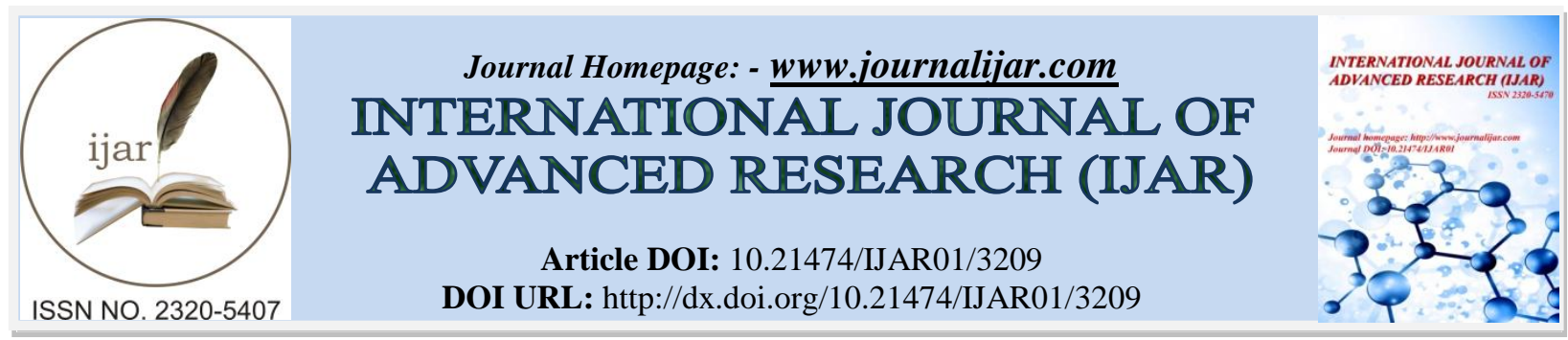

RESEARCH ARTICLE

\title{
THE LEVEL OF AWARENESS OF DIABETIC FOOT AMONG PATIENTS WITH TYPE 2 DIABETES MELLITUS (T2DM) IN ALAHSA, SAUDI ARABIA.
}
Mohamed Riched Nabouli Asst Prof, Ali Hussain Al Rasasi MBBS, Mohammed Saleh AI Saeed MBBS and Mohammed Fahd Al Momen MBBS and Asma Saleh Alsaeed MBBS.

King Faisal University, college of Medicine.

\section{Manuscript Info}

Manuscript History

Received: 18 December 2016

Final Accepted: 24 January 2017

Published: February 2017

\section{Abstract}

Introduction and background: Diabetic foot disease is a major challenge for the healthcare system, with enormous economic consequences for people living with diabetes, their families, and society, affecting both quality of life as well as the quality of care. The burden of diabetes and its foot complications is increasing in Saudi Arabia. Prevention of these complications through foot care education should be explored. The objectives of this study is assessing the level of awareness of diabetic foot among patients with type 2 diabetes mellitus (T2DM) .In addition to finding the effectiveness of health education in improving foot care practice among diabetes patients in $\mathrm{Al}$ Ahsa .

Methodology: A cross-sectional study was conducted among patients with T2DM .The study involved 360 diabetic patients who attended diabetic clinics in Al Ahsa city, Saudi Arabia between January 2016 to November 2016. Structured questionnaire was used to assess their knowledge and practices regarding foot care. The questioners containing 9 parts involving age, sex, educational level, economic status , duration of DM, current complications , any surgical intervention for the foot and foot care practices. The data analyzed using SPSS 20 version software. Appropriate statistical tests used to analyzed the data .

Result : The study involved 360 patients with T2DM. Out of the total sample, $221(61,4 \%)$ were male and $139(38,6 \%)$ were female. There education levels were $(24,4 \%)$ illiterate, $(33,3 \%)$ elementary, $(13,3 \%)$ secondary, $(13,1 \%)$ higher, and $(16,1 \%)$ academic. $70 \%$ of them had middle income. $(16,7 \%)$ of the participants had previous foot injury due to diabetes. Less than half of the participants $147(40,9)$ obtained an awareness about diabetic foot injury. $214(59,6 \%)$ reported having basic knowledge about diabetic foot injuries were the rest did not have basic knowledge. Educational level $(\mathrm{p}=0,001)$ and household income $(p=0,001)$ had a significant impact on knowledge about diabetic foot injuries.

Conclusion: The results from our study revealed that patients were unaware of diabetes foot risk factors and the importance of foot care practice to their health. Awareness programs should be implemented in all hospitals to help to overcome the paucity of knowledge among the 
participants coupled with regular assessment of the patients foot at each visit to the diabetic clinic.

Copy Right, IJAR, 2017,. All rights reserved.

\section{Introduction and Background:-}

Diabetes mellitus is common chronic disease, affecting nearly all the population in the developing and developed countries .Worldwide, more 120 million people affected by diabetes mellitus. It is expected that this number will reach to 250 million by the year 2050 (1). In Saudi Arabia, more than 25 percent of adult population over 30 years of age is suffering from diabetes mellitus and by the year 2030 this number will be more than double. (2) Diabetes mellitus complications especially diabetic foot problems are a major cause of morbidity and premature mortality. Annually around 3.2 million deaths in the world occurs as result of Diabetes mellitus complications. (3-4) 20 percent of diabetic hospitalizations are attributed to diabetic foot problems. The risk of lower limb amputation is found to be 10 to 15 times higher among diabetic patients compared with non-diabetics. (5)

Diabetic foot disease considered as a major challenge for the healthcare system, with enormous economic consequences for people living with diabetes, their families, and society, affecting both quality of life and quality of care. (2) The burden of diabetes and its foot complications is increasing in Saudi Arabia which demanding for effective prevention strategies.

The studies have revealed that there is marked correlation between the level of awareness of diabetic foot lesions and reduction of its occurrence rate. proper education of patients regarding the foot care and awareness of diabetic foot disease have shown to achieve a marked reduction in the limb amputation rate. it reduced the amputation rate by half in addition to minimizing the rate diabetic foot hospitalization and its burden. (5-8) since education of patient about diabetic foot care is considered as a mainstay of prevention for the diabetic foot complications by many Literatures. This study aimed to assess the level of awareness of diabetic foot among patients with type 2 diabetes mellitus (T2DM). In addition to finding the effectiveness of health education in improving foot care practice among diabetes patients in Alhasa city.

\section{Methodology:-}

\section{Study design and setting:-}

A cross-sectional study was conducted among diabetic patients. The study involved 360 diabetic patients who attended diabetic clinics in Alhasa city, Saudi Arabia between January 2016 to November 2016. The sample size calculated by using Rosoft website, with a margin of error of 5\%, and confidence interval of $95 \%$.

\section{Data collection:-}

Structured questionnaire was used to assess their knowledge and practices regarding foot care. The questioners containing 9 parts, (a) personal data ( age, gender, educational background, socioeconomic status and Province ), (b) duration of DM, (c) current complications ( retinopathy, nephropathy, Diabetic neuropathy, stroke, coronary artery disease (CAD) and peripheral artery disease (PAD)), (d) prior foot or leg problem, (e) surgical intervention for the foot, (f) current treatment for DM ,(g) Hb A1c level, (h) Self-assessment of the Feet, (i) duration of foot washing,

(j) Walking barefoot, (k) foot care practices (using nail clipper, warming feet in the winter ,checking water temperature before feet washing, using herbal medication ,wearing comfortable footwear), (l) patients knowledge about diabetic foot disease and its risk factors ( the patient should indicate the source of information), (m) number of feet examination by doctor. After obtaining a written consent, the patients were asked to check the appropriate boxes for the questions. the questionnaire translated to Arabic to ensure full understanding of questions by the patients.

\section{Statistical analysis:-}

The data analyzed using Statistical Package for Social Sciences version 22 Descriptive analysis was carried out to analyze the date. In addition to chi-square test and t-test which done tounderstand the variables associated with awareness of Diabetic foot problems. The data checked at $95 \%$ confidence interval (CI) and significant level of pvalue of $<0.05$. 


\section{Result:-}

A total of 360 diabetic patients were involved in the study. The mean age of the respondents was 57,2 years .out of 360 respondents, $221(61,4 \%)$ were male and $139(38,6 \%)$ were female. AAround one third $(33.3 \%)$ of the sample was having elementary education and one quarter $(24,4 \%)$ of the sample was illiterate. Only $16,1 \%$ completed university. The majority $(76,45 \%)$ of them were living in city and $23,6 \%$ was living in village. regarding the household income around $70 \%$ were having middle income. ( Table 1)

Table 1:- Demographic characteristics of study population .

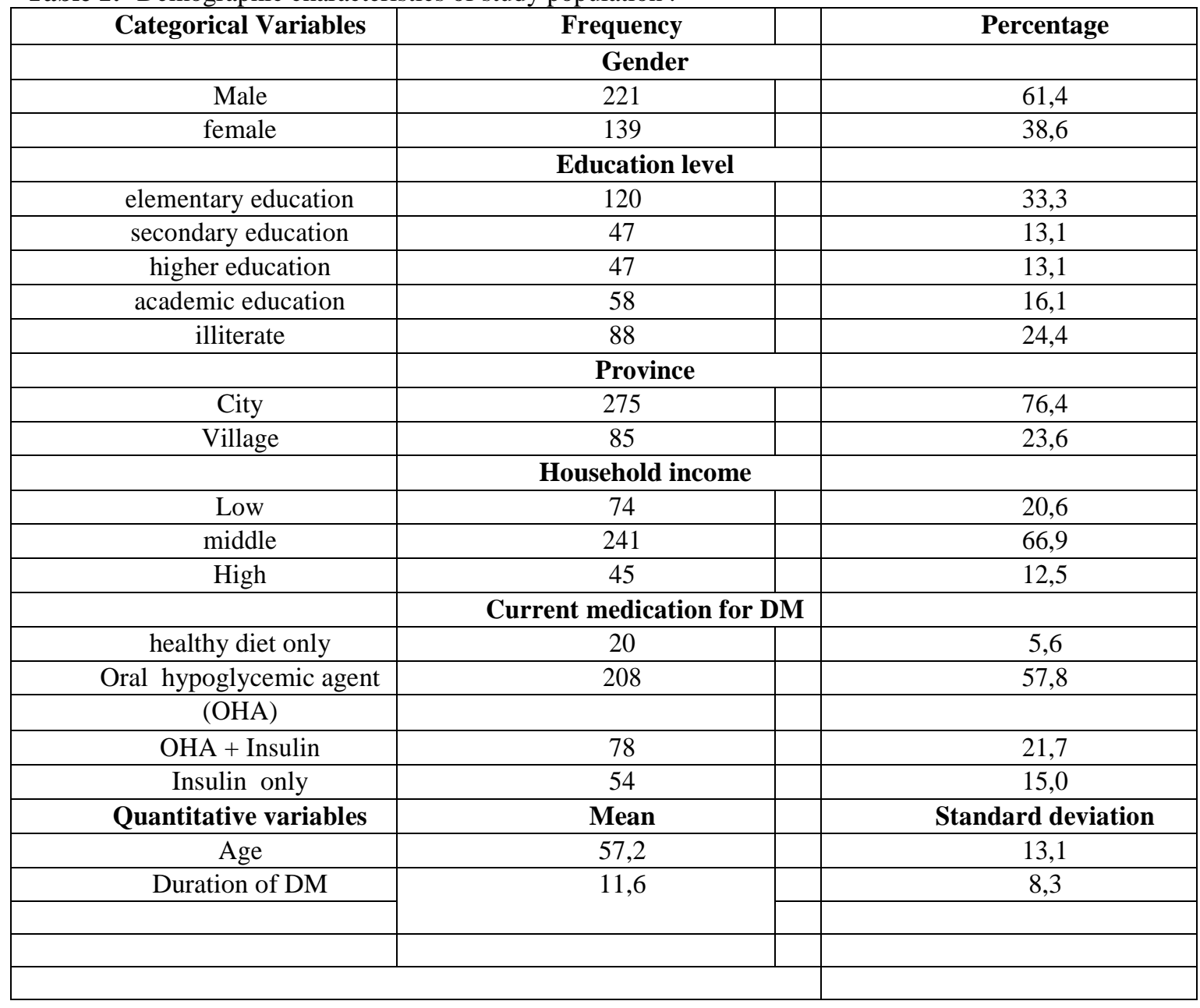

The mean duration of diabetes was 11,6 years. More than half $(57,8 \%)$ of responders were using oral hypoglycemic agent only, 21,7\% were using oral hypoglycemic agent in combination with insulin, 15,0\% were using insulin alone and only few $(5,6 \%)$ of them were following diabetic diet only. (table 1)

Regarding the diabetic complications, large number of patients were suffering from retinopathy $145(40,3 \%)$ and Peripheral Neuropathy $84(23,3 \%)$. Other complications were reported with lower frequencies $52(14,4 \%)$ Diabetic Peripheral Artery Disease of feet , $46(12,8 \%)$ Nephropathy , $29(8,1 \%)$ Brain stroke , $26(7,2 \%)$ Coronary artery disease $.141(39,2 \%)$ were not suffering from any complications . (table 2)

The greatest number of respondents $300(83,3 \%)$ had no any previous foot injury due to diabetes were 60 (16,7\%) only had previews foot injury due to diabetes. Around half of the participants who suffered from diabetic feet injury undergo feet surgery . ( table 2 ) 
Table 2:- distribution of diabetic complications, diabetic feet injury and surgery among participants.

\begin{tabular}{|c|c|c|}
\hline Variable(s) & Frequency & 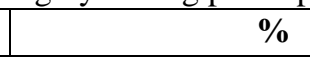 \\
\hline & Retinopathy & \\
\hline yes & 145 & 40,3 \\
\hline \multirow[t]{2}{*}{ no } & 215 & 59,7 \\
\hline & Peripheral Neuropathy & \\
\hline yes & 84 & 23,3 \\
\hline \multirow[t]{2}{*}{ no } & 276 & 76,7 \\
\hline & \multicolumn{2}{|c|}{ Diabetic Peripheral Artery Disease of feet } \\
\hline yes & 52 & 14,4 \\
\hline \multirow[t]{2}{*}{ no } & 308 & 85,6 \\
\hline & Nephropathy & \\
\hline yes & 46 & 12,8 \\
\hline \multirow[t]{2}{*}{ no } & 313 & 87,2 \\
\hline & Brain stroke & \\
\hline yes & 29 & 8,1 \\
\hline \multirow[t]{2}{*}{ no } & 331 & 91,9 \\
\hline & Coronary artery disease & \\
\hline yes & 26 & 7,2 \\
\hline \multirow[t]{2}{*}{ no } & 333 & 92,5 \\
\hline & Previous feet injury due to diabetes & \\
\hline yes & 60 & 16,7 \\
\hline \multirow[t]{2}{*}{ no } & 300 & 83,3 \\
\hline & Previous feet surgery due to diabetes & \\
\hline Yes & 31 & 8,6 \\
\hline No & 329 & 91,4 \\
\hline
\end{tabular}

Regarding foot care, some practices were taken into consideration such as using nail clipper, monitoring water temperatures, drying the feet after each exposure to water, warming the feet during winter, using herbs to treat the feet, wearing cotton socks, wearing comfortable closed shoes, self-examination of the foot , duration of foot washing with water and walking barefooted. Of the total sample, Almost all the respondents 352 (98,1\%) used nail clippers to cut their nails, $302(48,1 \%)$ monitored water temperature before washing foot or shower ,167 $(46,5 \%)$ dried their feet after water exposure , $314(87,5 \%)$ kept their feet warm during winter, $258(71,9 \%)$ of the respondents wore comfortable cotton socks , $242(67,4 \%)$ wore closed comfortable shoes and 338 (94,2\%) did not use herbs to treat their feet . Regarding self-examination of the foot, $81(22,5 \%)$ of the participants perform it regularly, were $196(54,4 \%)$ perform it in case of pain and $83(23,1 \%)$ don not perform self-examination at all. (table 3).Considering duration of foot washing with water, three quarters of the participants $275(67,4 \%)$ washed for less than 5 minutes. $67(18,6 \%)$ of the participants wash from 5 to 10 minutes. The least number of participants $18(5 \%)$ wash for longer than 10 minutes. The majority of the respondents $253(70,3 \%)$ do not walk barefooted, were $106(29,4 \%)$ of the do walk barefooted .(table 3$)$ 
Table 3: -diabetic foot care practices among the participants.

\begin{tabular}{|c|c|c|}
\hline Variables & Frequency & $\%$ \\
\hline \multicolumn{3}{|c|}{ Self-examination of the foot } \\
\hline not at all. & 83 & 23,1 \\
\hline in case of pain & 196 & 54,4 \\
\hline regularly & 81 & 22,5 \\
\hline \multicolumn{3}{|c|}{ Duration of foot washing with water } \\
\hline less than 5 minutes & 275 & 76,4 \\
\hline from 5 to 10 minutes & 67 & 18,6 \\
\hline more than 10 minutes & 18 & 5,0 \\
\hline \multicolumn{3}{|l|}{ Walking barefoot } \\
\hline yes & 106 & 29,5 \\
\hline no & 253 & 70,5 \\
\hline \multicolumn{3}{|c|}{ Using nail clipper to cut nails } \\
\hline yes & 352 & 98,1 \\
\hline no & 7 & 1,9 \\
\hline \multicolumn{3}{|c|}{ Monitoring water temperature before washing } \\
\hline \multicolumn{3}{|c|}{$\begin{array}{c}\text { foot or shower } \\
\end{array}$} \\
\hline yes & 302 & 84,1 \\
\hline no & 57 & 15,9 \\
\hline \multicolumn{3}{|c|}{ Drying feet after each exposure to water } \\
\hline yes & 167 & 46,5 \\
\hline no & 192 & 53,5 \\
\hline \multicolumn{3}{|l|}{ Warming feet in winter } \\
\hline yes & 314 & 87,5 \\
\hline no & 45 & 12,5 \\
\hline \multicolumn{3}{|c|}{ Using herbs to treat the feet } \\
\hline yes & 21 & 5,8 \\
\hline no & 338 & 94,2 \\
\hline \multicolumn{3}{|c|}{ Wearing comfortable cotton socks } \\
\hline yes & 258 & 71,9 \\
\hline no & 101 & 28,1 \\
\hline \multicolumn{3}{|c|}{ Wearing comfortable and closed Shoes } \\
\hline yes & 242 & 67,4 \\
\hline no & 117 & 32,6 \\
\hline
\end{tabular}


More than half the respondents 214 (59,6\%) had knowledge about diabetic foot injuries, were the rest 146 (40,4\%) did not have knowledge about diabetic foot injuries. $212(59,1 \%)$ of the respondents reported obtaining proper awareness about diabetic foot injuries, $147(40,9 \%)$ did not obtain any awareness .The majority of patients who reported obtaining proper awareness they obtain it from doctors $83(56,5 \%)$, while the rest of them obtain it from other sources ; nurse $11(7,5 \%)$, relatives $32(21,8 \%)$, social media $27(18,4 \%)$, or $19(12,9 \%)$ health education campaign. (table 4)

Table 4:- source of awareness among the participants who obtained an awareness

\begin{tabular}{|c|c|c|}
\hline Source of awareness & Frequency & $\%$ \\
\hline Doctor & & 56,5 \\
\hline yes & 83 & 43,5 \\
\hline no & 63 & 7,5 \\
\hline Nurse & 11 & 92,5 \\
\hline yes & 135 & 21,8 \\
\hline no & & 78,2 \\
\hline Relatives & 32 & 18,4 \\
\hline yes & 114 & 81,6 \\
\hline no & & \\
\hline Social Media & 27 & 12,9 \\
\hline yes & 119 & 87,1 \\
\hline no & & \\
\hline Health educational campaign & 19 & \\
\hline yes & 127 & \\
\hline no & & \\
\hline
\end{tabular}

Around one third of the respondents $125(34,7 \%)$ have basic knowledge about the risk factors of diabetic foot injury, while the majority $235(65,3 \%)$ of them were lacking of these basic knowledge. The knowledge of the patient who reported having basic knowledge about the risk factors of diabetic foot injury were furtherly assessed by asking them to select one or more of the following if they think that it could be a risk factor ; duration of foot washing, walking bare foot, and wearing inappropriate shoes Out of the $125(34,7 \%), 79(63,2)$ of them thought that the duration of foot washing increases the risk of diabetic foot injury, as $62(49,6)$ of them thought that walking bare foot do. While only $39(31,2)$ of them thought that wearing inappropriate shoes is a risk factor. (table 5)

Table 5:- Assessment of the participants' knowledge about the risk factors of diabetic foot injuries

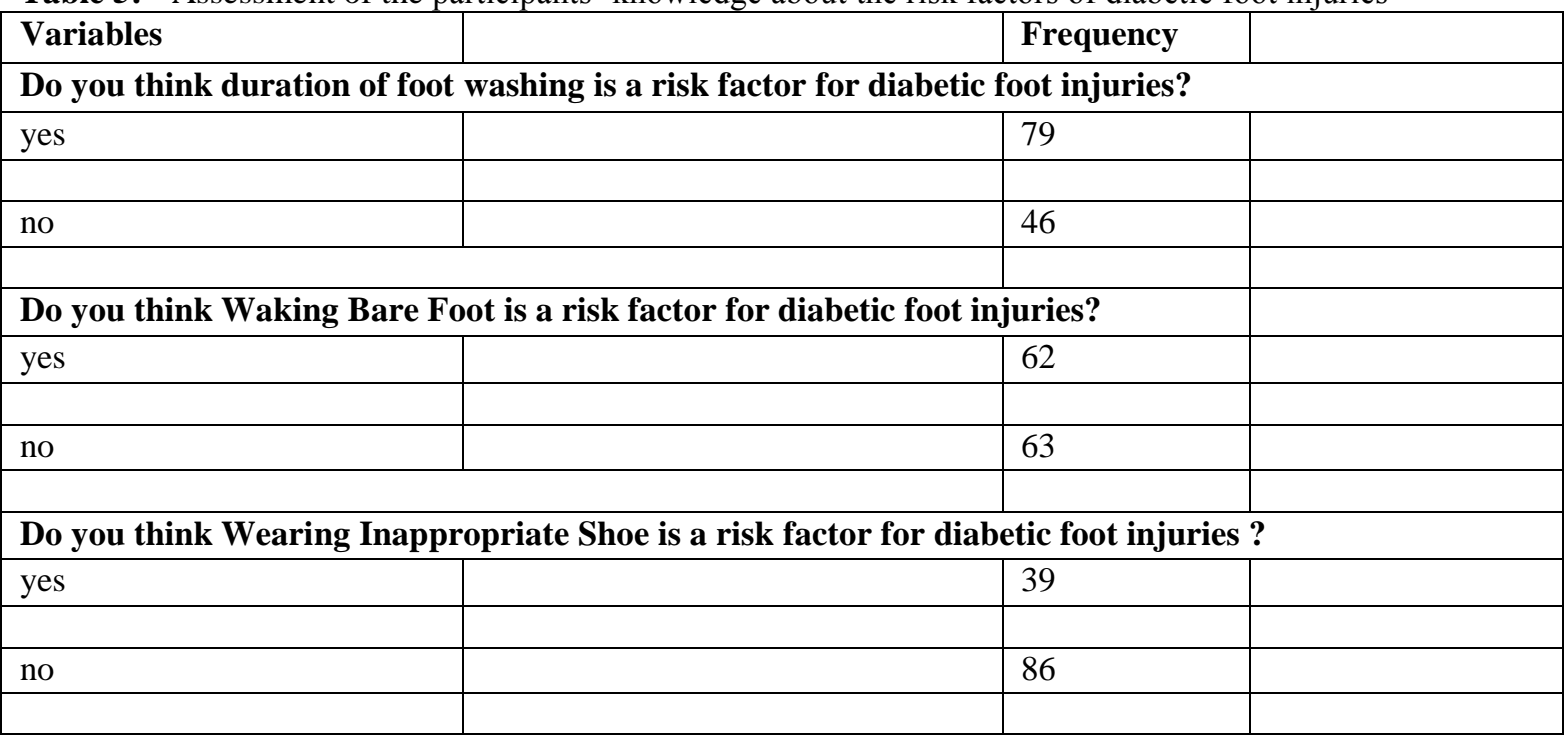


Most of the participants $236(65,6 \%)$ indicated that they received foot examination by a doctor only if they have a complaint, were $63(17,5 \%)$ will get their feet examined at each visit to the doctor, and 61 (17\%) will not examine even in case of a complaint. (Table 6)

Table 6:- foot examination by doctor among the participants.

\begin{tabular}{|c|c|c|}
\hline Variables & Frequency & $\%$ \\
\hline At Each Visit To The Doctor & 63 & 17,5 \\
\hline If There Is A Complaint & 236 & 65,6 \\
\hline Not Examine Even With Complaint & 61 & 16,9 \\
\hline
\end{tabular}

Gender $(\mathrm{p}=0.07)$ and province $(\mathrm{p}=0.9)$ of the participants did not show a significant impact on patients' knowledge about diabetic foot injuries. While the educational level of the participants $(p=0,001)$ and household income $(p=0,001)$ had shown a significant impact on patients' knowledge about diabetic foot injury(.table 7)

Table 7:- Relationship of knowledge with gender ,educational status, province and household income.

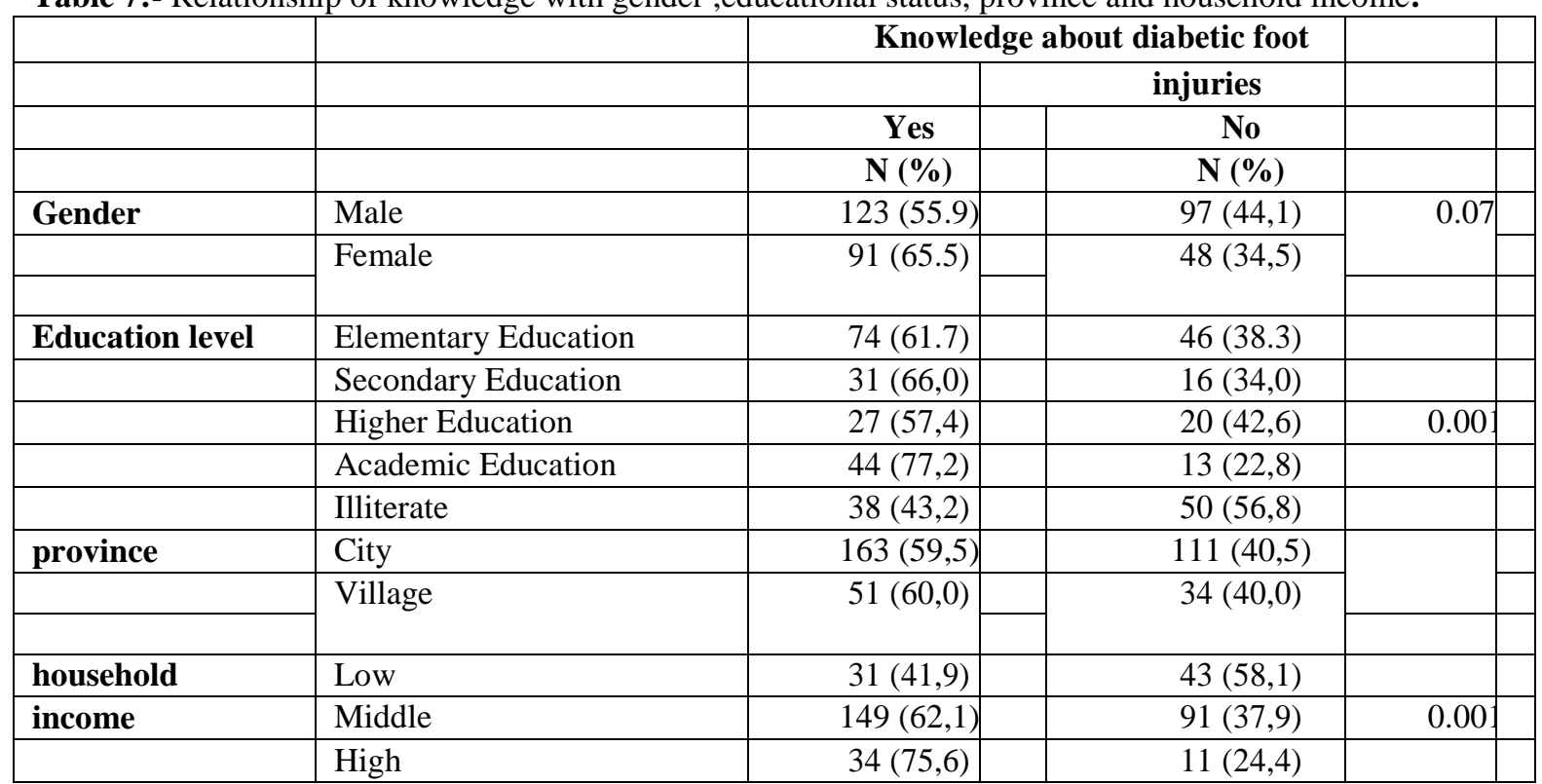

Previous feet injury ( $\mathrm{p}=0,131)$, previous feet surgery $(\mathrm{p}=0,560)$ due to diabetes were not significantly associated with better knowledge or foot care practices (table 8$)$.

Table 8:- Relationship of knowledge with varies diabetic complications, Previous diabetic foot injury and Previous feet surgery due to diabetes

\begin{tabular}{|c|c|c|c|c|c|c|}
\hline & & \multicolumn{4}{|c|}{ Knowledge about diabetic foot } & \multirow[t]{2}{*}{$\mathbf{p}$} \\
\hline & & & injuries & & & \\
\hline & & Yes & & No & & \\
\hline & & \multicolumn{2}{|c|}{$\mathbf{N}(\%)$} & \multicolumn{2}{|c|}{$\mathrm{N}(\%)$} & \\
\hline \multirow[t]{2}{*}{ Retinopathy } & Yes & 85 & $(59,0)$ & 59 & $(41,0)$ & \multirow[t]{2}{*}{0.8} \\
\hline & No & 129 & $(60,0)$ & 86 & $(40,0)$ & \\
\hline \multirow[t]{2}{*}{ Nephropathy } & Yes & 23 & $(50.0)$ & 23 & $(50.0)$ & \multirow[t]{2}{*}{0.1} \\
\hline & No & \multicolumn{2}{|c|}{$191(61,2)$} & \multicolumn{2}{|c|}{$121(38,8)$} & \\
\hline \multirow[t]{2}{*}{ Peripheral Neuropathy } & Yes & 36 & $(42,9)$ & 48 & $(57,1)$ & $<10^{-}$ \\
\hline & No & 178 & $(64,7)$ & 97 & $(35,3)$ & 4 \\
\hline Coronary artery disease & Yes & 10 & $(38,5)$ & 16 & $(61,5)$ & 0.02 \\
\hline
\end{tabular}




\begin{tabular}{|c|c|c|c|c|c|c|}
\hline & No & 203 & $(61,1)$ & 129 & $(38,9)$ & \\
\hline Brain stroke & Yes & 14 & $(48,3)$ & 15 & $(51,7)$ & \multirow[t]{2}{*}{0.1} \\
\hline & No & 200 & $(60,6)$ & 130 & $(39,4)$ & \\
\hline \multirow[t]{2}{*}{ Peripheral Artery Disease of feet } & Yes & 28 & $(53,8)$ & 24 & $(46,2)$ & \multirow[t]{2}{*}{0.3} \\
\hline & No & 186 & $(60,6)$ & \multicolumn{2}{|c|}{$121(39,4)$} & \\
\hline \multirow[t]{2}{*}{ Previous diabetic foot injury } & Yes & 41 & $(68,3)$ & 19 & $(31,7)$ & \multirow[t]{2}{*}{0.1} \\
\hline & No & 173 & $(57,9)$ & 126 & $(42,1)$ & \\
\hline \multirow{2}{*}{$\begin{array}{l}\text { Previous feet surgery due to } \\
\text { diabetes }\end{array}$} & Yes & 20 & $(64,5)$ & 11 & $(35,5)$ & \multirow[t]{2}{*}{0.5} \\
\hline & No & 194 & $(59,1)$ & 134 & $(40,9)$ & \\
\hline
\end{tabular}

Some foot care practices such as duration of foot washing with water $(\mathrm{p}=0,719)$, using nail clipper to cut nails $(\mathrm{p}=0,362)$, monitoring water temperature $(\mathrm{p}=0,552)$, warming feet in winter $(\mathrm{p}=0,703)$, wearing comfortable cotton socks $(\mathrm{p}=0,314)$, and closed shoes $(\mathrm{p}=0,076)$ did not show any correlation with patients'knowledge about diabetic foot injury. The patients performed these practices despite their poor background knowledge. This result wasn't consistence with the result of other studies.(4)

Regarding self-examination of foot, there is no marked correlation between self-

\begin{tabular}{|c|c|c|c|c|c|c|c|}
\hline examination of foot with & here is & th gende & $=0.9)$, & lucation & anc & age & $(\mathrm{p}=.1)$, the \\
\hline percentage of self-exam & on negl & ence & was & most the & bet & ween $\mathrm{m}$ & and female \\
\hline participants . (table 9) & & & & & & & \\
\hline & & & & & & & \\
\hline & & Self-ex & inatio & of foot & & & $\mathrm{p}$ \\
\hline & Not a & & In ca & & $\operatorname{Reg}$ & ularly & \\
\hline & & & & pain & & & \\
\hline Gender & & $\mathbf{N}(\%)$ & & $\mathrm{N}(\%)$ & & $\mathbf{N}(\%)$ & \\
\hline Male & 51 & $(23,1)$ & 121 & $(54,8)$ & 49 & $(22,2)$ & 0.9 \\
\hline Female & 32 & $(23,0)$ & 75 & $(54,0)$ & 32 & $(23,0)$ & \\
\hline Education level & & & & & & & \\
\hline Elementary education & 24 & $(20,0)$ & 68 & $(56,7)$ & 28 & $(23,3)$ & 0.2 \\
\hline Secondary education & 15 & $(31,9)$ & 21 & $(44,7)$ & 11 & $(23,4)$ & \\
\hline Higher education & 9 & $(19,1)$ & 26 & $(55,3)$ & 12 & $(25,5)$ & \\
\hline Academic education & 8 & $(13,8)$ & 37 & $(63,8)$ & 13 & $(22,4)$ & \\
\hline Illiterate & 27 & $(30,7)$ & 44 & $(50,0)$ & 17 & $(19,3)$ & \\
\hline & Meal & SD) & Mea & (SD) & Me & n (SD) & \\
\hline Age & 58.8 & $(12.5)$ & 57.5 & $(13.6)$ & 57.2 & $(13.1)$ & 0.1 \\
\hline
\end{tabular}

\section{Discussion:-}

Our current finding revealed that over half of the participants had a basic knowledge about diabetic foot injury. The majority of these knowledgeable participants were having high household income in addition to having an academic degrees. only minority of them were illiterate. the educational level $(\mathrm{p}=0,001)$ and household income $(\mathrm{p}=0,001)$ of the participants had shown an impact on patients' knowledge about diabetic foot injury .The results of our study exposed that the most educated patients are the most knowledgeable about diabetic foot injuries, which come in consistence with the results of other studies. [3,6]

The majority $(57,8 \%)$ of responders were on oral hypoglycemic drugs alone or in combination with insulin $(21,7 \%)$. A smaller number $(15,0 \%)$ were on insulin therapy alone. only little number of participants $(5,6 \%)$ was on diabetic 
diet. Among these participants, the mean $\mathrm{Hb}$ A1C level was $(7,8)$ which indicates that their serum glucose level is not well controlled. This could be a result of medication adherence failure due to lacking of knowledge about the importance of taking medication on regular pattern .

Foot care practices did not show any correlation with patients' knowledge about diabetic foot injury. The patients performed these practices despite their poor background knowledge.. A study have found similar result and attributed this result to basis of Islamic rituals .patients were performing some of these practice religiously without knowing their benefits to their own health

Worldwide, there are more than 1 million lower extremities amputation (LEA) surgery per year, at the rate of one every 30 seconds .(9) up to 50\% of the diabetic patients require another lower LEA within 3-5 years from the first LEA . Furthermore, the 5-year mortality rate after LEA on diabetic patients is $~ 50 \%$ (10). despite these facts , only $63(17,5 \%)$ of patients received foot examination at each visit to the doctors and similar percents 61 (17\%) of patients had not received any examination even if they had a complaint. additionally, our study reveled that there is a paucity of knowledge among participants with previous foot injuries and surgeries due to diabetes. Previous feet injury $(\mathrm{p}=0,131)$ and previous feet surgery $(\mathrm{p}=0,560)$ due to diabetes were not significantly associated with better knowledge or foot care practices. This result is similar to the result of study done in India. (11) .Taking in consideration that up to up to $85 \%$ of the LEA are completely preventable by simple foot care practices , (12) diabetic patients are in need for effective awareness strategies taken by medical facilities .

More than half of the respondents $214(59,6 \%)$ reported having knowledge about diabetic foot injuries .But when they further asked about the risk factors diabetic foot injuries ,Most of them $(64,9 \%)$ were found to be lacking of knowledge about the risk factors. The rest of them were found to have poor knowledge about the risk factors.

Duration of having diabetic mellitus was believed to be as a risk factor by $(63,2 \%)$, were walking bare foot (49,6\%) and wearing inappropriate shoes $(31,2)$ was the lest to be known as risk factors. Which approves the result of a study carried out in Africa. (13) $212(59,1 \%)$ of the respondents reported obtaining proper awareness about diabetic foot injuries. The majority of them obtained their awareness from doctors $83(56,5 \%)$ and relatives $32(21,8 \%)$, while the least number of them obtained it either from social media $27(18,4 \%)$ or health education campaign 19 $(12,9 \%)$.on the other hand , $147(40,9 \%)$ of the participants did not obtain any awareness . Indicated that the Saudi population need to be aware on the problem size and its impact on the quality of life. There should be awareness campaigns in the hospitals, public area and on social media coupled with educational programmers at the schools and universities ,to highlight the risk factors of diabetic foot injuries and put more emphasis on the urgent need for serious preventive strategies. Furthermore, The provided information through the educational programs should correspond with educational background of patients without affecting the amount or the quality of the provided information .

\section{Conclusion:-}

The results from our study revealed that patients are unaware of diabetes foot risk factors and the importance of foot care practices to their health. Awareness programs should be implemented in all hospitals to help to overcome the paucity of knowledge among the participants coupled with regular assessment of the patients foot at each visit to lower the rate of diabetic foot injuries . in addition to enhancing the role of educational campaigns and social media in improving the level of awareness among Saudi population . furthermore, serious preventive steps should be taking by the Saudi population and ministry of health to lower the risk of diabetic foot injuries as well as the complication of T2DM.

\section{Acknowledgment:-}

The authors express their sincere thanks to Syed Sibt-ul-Hasnain Iheb Bougmiza, Associate Professor of Preventive \& Community Medicine for his contribution in the statistical analysis of data . We are also thankful to the diabetic patients for their cooperation and participation in this survey . 


\section{References:-}

1. Abdullah M Alwahabi.The diabetic foot in the Arab World.Saudi Med J 2006,27(2):147-153

2. Ahmed S. Awareness of Diabetic Foot among Type 2 Diabetes in a Tertiary Care Hospital, Saudi Arabia: A Cross-Sectional Study. Endocrinology\&Metabolism International Journal. 2016;3(5).

3. Al Odhayani A, Al Sayed Tayel S, Al-Madi F. Foot care practices of diabetic patients in Saudi Arabia. Saudi Journal of Biological Sciences. 2015

4. Hasnain S, Sheikh NH. Knowledge and practices regarding foot care in diabetic patients visiting diabetic clinic in Jinnah Hospital, Lahore. JPMA 2009; 59(10):687-690 .

5. Yavuz DG, Tuglular S, Ersoz HO, Altun A, Archer A, Akalin S. Awareness of diabetic foot disease in a group of Turkish and English patients with type 2 diabetes mellitus: assessment of the status and the efficacy of diabetic foot education. Turk J Endocrinol Metab 1999;2:65-70.

6. Farasat T, Sharif S, Manzoor F, Zafar M, Naz S. Prevalence of Retinopathy Detected by Fundoscopy among Newly Diagnosed Type 2 Diabetic Patients Visiting a Local Hospital in Lahore. Pakistan Journal of Zoology. 2017;49(1):345-349.

7. Saurabh S, Sarkar S, Selvaraj K, Kar S, Kumar S, Roy G. Effectiveness of foot care education among people with type 2 diabetes in rural Puducherry, India. Indian Journal of Endocrinology and Metabolism. 2014;18(1):106

8. Ekore R, Ajayi I, Arije A, Ekore J. Knowledge of and attitude to foot care amongst Type 2 diabetes patients attending a university-based primary care clinic in Nigeria. African Journal of Primary Health Care \& Family Medicine. 2010;2(1).

9. Kung H-C, Hoyert DL, Xu J, Murphy SL. Deaths: Final data for 2005. Natl Vital Stat Rep 2008;56(10):1-120.

10. Rodrigues B, Vangaveti V, Malabu U. Prevalence and Risk Factors for Diabetic Lower Limb Amputation: A Clinic-Based Case Control Study. Journal of Diabetes Research. 2016;2016:1-7.

11. Chellan G, Srikumar S, Varma A, Mangalanandan T, Sundaram K, Jayakumar R et al. Foot care practice - The key to prevent diabetic foot ulcers in India. The Foot. 2012;22(4):298-302.

12. International Diabetes Federation (2005) cited in 'Diabetes and your feet: A guide to maintaining healthy feet for people with diabetes', (2009) The Society of Chiropodists and Podiatrists.

13. Goie TNaidoo M. Awareness of diabetic foot disease amongst patients with type 2 diabetes mellitus attending the chronic outpatients department at a regional hospital in Durban, South Africa. African Journal of Primary Health Care \& Family Medicine. 2016;8(1). 